\title{
Introducing Mnemonics to Japanese Students as a Vocabulary Learning Strategy
}

\author{
Stephen Paton \\ Fukuoka University
}

\begin{abstract}
Mnemonic strategies are not often utilised by Japanese students to learn and consolidate vocabulary, despite research showing that they are particularly effective. As part of an informal action research process, a structured lesson plan was devised that would introduce mnemonic strategies indirectly, that is, not by applying them directly to second-language vocabulary study from the outset, but instead as a means of memorising simple word/number pairings in something of a game. The strategy's applicability to vocabulary study was shown only after it had been witnessed and practised by the students. This lesson was given in numerous classes from a variety of academic disciplines. A survey of the students $(n=361)$ was later carried out to ascertain whether despite its initially bypassing second-language concerns and complications, the lesson had been effective in introducing mnemonics as a vocabulary learning strategy that the students might choose to utilise in an upcoming programme of vocabulary learning and testing. Responses indicated that the lesson had been highly effective and that students in similar contexts might benefit from being introduced to mnemonics in such a way.
\end{abstract}

\section{Introduction}

Students who utilise learning strategies learn more effectively than those who don't (Oxford, 1990; Rubin, 1975). Within the field of second-language vocabulary learning, a range of strategies exist for consolidating knowledge of the meanings of new words. Since the 1970s, research has shown that mnemonic approaches to second-language vocabulary learning are especially effective (Atkinson, 1975; Raugh \& Atkinson, 1975; Thompson, 1987). However, Japanese students of English tend to favour vocabulary consolidation strategies that are based on repetition and rote learning (Little \& Kobayashi, 2015; Schmitt, 1997), and persuading them to utilise mnemonic strategies can be difficult and ineffective.

As part of an ongoing informal action research investigation focused on discovering ways to effectively teach students to use mnemonics in their independent vocabulary study, a roughly 60-minute lesson was planned that aimed to demonstrate an adaptation of the mnemonic keyword method (Atkinson, 1975; Thompson, 1987). The lesson was comprised of firstly a "live" demonstration of the keyword method based not around second-language vocabulary but rather word/number pairings, then an activity in which students could experience the 
method for themselves entirely in their native language and, finally, an explanation and demonstration of the method's direct application in foreign-language vocabulary study. This lesson was presented to numerous classes of both first- and second-year students from various academic faculties.

To evaluate the effectiveness of this lesson sequence, particularly the use of native-language word/number pairings whose relevance to second-language vocabulary study may have been difficult for students to perceive, a survey was later administered as a means of ascertaining whether the lesson had successfully taught the strategy in a way that students could understand and appreciate and which might persuade them to utilise the strategy in their independent vocabulary study. The survey results strongly suggested that the lesson had been very effective, and that given the right introduction, students might be more amenable to taking advantage of mnemonic-based vocabulary learning strategies than observation and research would suggest.

\section{Literature Review}

Language learning strategies became a focus for educational researchers throughout the 1970s. Teacher skill and learner aptitude had been considered the major contributing factors to successful second-language acquisition; however, researchers became aware that the behaviours that learners adopted were better predictors of success (Rubin, 1975; Schmitt, 1997; Stern, 1975). Effective learning strategies were recognised and divided into three major types: (1) metacognitive strategies, which are used by learners to manage their own learning; (2) cognitive strategies, which are used to perform a specific language-centric task, such as repetition, translation and note-taking and (3) social/affective strategies, which are employed during actual communicative instances, such as asking for repetition and inferring meaning from the context (O’Malley \& Chamot, 1990). Oxford (1990) gave a more comprehensive categorisation, dividing strategies as belonging within memory, cognitive, compensation, metacognitive, affective and social delineations. Whilst strategies for building and expanding one's vocabulary would tend to fall into the memory and cognitive categories of both models, Schmitt (1997) determined that these models were inadequate when it came to categorising the considerable range of strategies employed in vocabulary learning. He created an exhaustive taxonomy of vocabulary learning strategies based on a broader dichotomy of determination and consolidation strategies. Determination strategies are those involved in discovering the meanings of words, whilst consolidation strategies comprise various memory, cognitive and metacognitive strategies by which to fix them in memory. According to Schmitt's (2000) own definition, vocabulary learning is a process of transferring lexical information from the short-term memory to the long-term memory; whilst other memory strategies listed in his taxonomy might be effective, such as using semantic maps, saying words out loud whilst studying, or using new words in sentences, research has shown that one of the most effective ways to create a strong connection within long-term memory is by figuratively attaching new lexical items to elements that are already firmly known. One of the first of such methods to be recognised by 
researchers was called the "keyword method" (Atkinson, 1975; O’Malley, Chamot, Stewner-Manzares, Kupper, \& Russo, 1985; Pressley, Levin, \& Miller, 1982a).

\subsection{Mnemonics and the keyword method}

Mnemonics are techniques or mental devices such as images, acronyms or rhymes that can help someone to both store and recall information in memory (Solso, 1995, cited in Pillai, 2004). They can be either visual or verbal. Mnemonics work by creating connections in memory between new information and existing information so that new information can be retained for a longer period.

Atkinson and Raugh (Atkinson, 1975; Raugh \& Atkinson, 1975) are certainly not credited with inventing the field of mnemonics, which dates back to thousands of years, nor with carrying out the first research into the efficacy of mnemonics-based memorisation in education (see, e.g., Ott, Butler, Blake, \& Ball, 1973, as cited in Pressley, Levin, \& Delaney, 1982b). The "keyword method," though, which was introduced in Atkinson's (1975) article "Mnemotechnics in second-language learning," has formed the basis of much of the research surrounding educational applications of mnemonics. Pressley et al. (1982b) describe Atkinson's keyword method as:

a two-stage process for learning foreign vocabulary words. To use the technique, one first derives a keyword, which is an [L1] word... that sounds like part of the foreign word... Then a meaningful interaction involving the keyword and the vocabulary word's definition... is constructed. This can be in the form of a provided interactive illustration, or the learner can generate an interactive visual image. (p. 62)

The example is given about the Spanish word carta, meaning "postal letter," being connected to the English keyword "cart," with a suggested mental image of a postal letter being conveyed in a shopping cart. In their 1975 experiments, Raugh and Atkinson showed that the keyword method was highly effective in L2 vocabulary acquisition (Raugh \& Atkinson, 1975, cited in Amiryousefi \& Ketabi, 2011).

The keyword method has gone through a great deal of research scrutiny since the 1970s. Amiryousefi and Ketabi (2011) carried out a comprehensive review of literature from across the decades and concluded that "[m]nemonics have been proven to be extremely effective in helping people remember things... If material is presented in a way which fits in or relates meaningfully to what is already known, then it will be retained for relatively long periods of time and thus retrieval through verbal or visual clues becomes quite easy" (p. 179). Many studies have compared the effectiveness of the keyword method with that of such strategies as semantic-context learning (Wang \& Thomas, 1995) and rote memorisation (Brahler \& Walker, 2008), and found that the keyword method groups consistently outperformed the others on both immediate and delayed tests.

Shapiro and Waters (2005) examined the cognition underlying the effectiveness of the keyword method and concluded that imagery is a powerfully effective factor in learning and memorisation. Paul (1996, cited in Pillai, 2004) determined 
that people are likely to remember things that are unusual, outrageous or out of place - mechanisms of psychology that a mnemonic strategy is well-placed to leverage, and which potentially make mnemonics uniquely enjoyable and humorous amongst vocabulary consolidation strategies. Even though researchers have pointed out some shortcomings of the keyword method (Barcroft, Sommers, \& Sunderman, 2011; van Hell, \& Mahn, 1997), such as latencies in the recall process, the necessity of skills in encoding effective connections and complications arising from the differences in phonemic characteristics of different languages, a general consensus seems to have been reached amongst researchers that the keyword method is a particularly effective vocabulary learning strategy.

\subsection{Strategies in use in Japan}

Despite mnemonics being found to be enjoyable and effective, Schmitt's (1997) research revealed that Japanese students tend not to utilise mnemonic techniques when consolidating new vocabulary knowledge. In his survey of Japanese learners, the three highest-rated vocabulary consolidation strategies in terms of perceived helpfulness were written repetition, verbal repetition and continuing to study over time (more repetition). Recent research suggests that not much has changed in the last several decades, with Japanese students being less familiar with strategies that involve imagery, association and mnemonics (Little \& Kobayashi, 2015), and favouring, for example, list-learning over word cards (Kitano \& Chiba, 2019). Whatever the reason for those preferences, Japanese learners of English might be said to be missing out on the benefits that a mnemonic approach has been proven to facilitate.

\section{Background of the current study}

Over several years of assigning vocabulary learning and testing in many university English classes, and of explicitly teaching and encouraging the use of word cards (Paton, 2015), I had observed that most students indeed seemed to be using either no discernible vocabulary learning strategies or only repetition-based rote-learning ones. During the final few minutes of individual review and study before vocabulary tests, some students would write out some of the target words many times on paper, and others might simply read through their word lists without any discernible strategic approach. The students appeared to be unaware of, or had perhaps chosen to eschew, the kind of cognitive and metacognitive vocabulary learning strategies that have been shown to be most effective.

Some years ago, I began to search for ways to demonstrate and teach the use of mnemonics and the keyword method. While attempting to do so, a number of difficulties were quickly discovered. Primary amongst them was that most students were unaccustomed to the kind of lateral and creative thinking that mnemonics entails, and examples and explanations of mnemonics did not appear to be meaningful to the students. For example, explaining that a student of Japanese might learn the word natsu, meaning "summer," by creating a mental picture of eating nuts at the beach on a hot summer's day did not seem to be meaningful to many students. Even when examples of metaphorical imagery were 
comprehended for what they were, it appeared that examples of Japanese target words being encoded with English-based references were not helping to equip students to be able to create their own mnemonics (with Japanese language-based references) for their own study. Attempts to imagine and teach what might be interesting and useful mnemonics for English target words utilising phonemic or semantic references drawn from a Japanese speaker's mental and cultural lexicon were abandoned as having been pure speculation, as they were usually quite clearly ineffective. Requests to Japanese colleagues for assistance in creating example mnemonics from a Japanese speaker's point of view were discouraging, with several colleagues advising that since Japanese students simply do not think about vocabulary that way, attempting to find and create such mnemonics would not be worthwhile.

Taking an action research approach to these problems across some years, that is, taking action, observing its effect, reflecting on results and then planning re-formulated action (Burns, 2010), a search was undertaken for ways to both introduce the keyword method effectively and give the students immediate practical experience in creating and then quickly rehearsing their own mnemonics. At some stage, the idea of demonstrating the method using neither English nor Japanese target vocabulary, but instead utilising pairings of numbers and simple L1 vocabulary, arose. The particular form of a structured lesson plan that was eventually arrived at and to which this study was applied is detailed below.

\subsection{Treatment}

\subsubsection{Live demonstration}

The lesson began with a request that the students contribute to the creation of a list of 12 random English words. Firstly, examples of simple words that would be appropriate were given, such as dog, cat, eat or drink, and then students were invited to simply call out familiar words from their textbook or memory. As the words were called out, they were entered into the left column of a two-column spreadsheet table visible on the projector screen. Students were then asked to call out random numbers between 1 and 20, each of which was entered into the right column. Using a spreadsheet function, the 12 rows of the table were quickly sorted into the numerical order of the numbers column, resulting in a table resembling the one presented in Figure 1. Having created the table I quickly moved away from the computer, facing the students with my back to the projector screen, and told them that I was going to memorise the pairings of words and numbers. To make a more compelling and engaging demonstration, though, I was to do so without looking at the screen, and would therefore require that the students verbally teach me each of the pairings.

As each number-word pairing was read out by the students at my request, I would, invisibly to them, use a mnemonic approach to encode the pairing in a mental image, utilising as a memory tool either the physical shape of the numeral (a very long, thin number 1), or a rhyme (seven rhymes with heaven, thus mentally placing the object in heaven), or some such memory "hook" (e.g., the number 18 can be mnemonically associated with the concept of high school graduation, as 18 is the age at which that most often occurs). As the students taught me the pairings, 


\begin{tabular}{|c|c|}
\hline clock & 1 \\
\hline taxi & 2 \\
\hline believe & 3 \\
\hline monkey & 4 \\
\hline afternoon & 5 \\
\hline conversation & 7 \\
\hline question & 10 \\
\hline ladder & 11 \\
\hline correct & 12 \\
\hline birthday & 15 \\
\hline ice-cream & 18 \\
\hline dictionary & 20 \\
\hline
\end{tabular}

Figure 1. A student-produced list displayed on-screen and memorised by the teacher.

I would occasionally pause and recite back those that I had learnt so far, so as to rehearse retrieval and provide something of an update to the students. I would ask for clarification or repetition if necessary, make mistakes unabashedly, and take my time silently searching for effective mnemonic hooks for each pairing. In class after class, students would watch, apparently captivated, as though they were witnessing a tight-rope walk in progress. Once all 12 pairings had been given and encoded, I would cover my eyes and recite the list both upwards and downwards once or twice, very often eliciting actual applause from the students. This stage usually took around 4-5 minutes.

Next, the students were to "test" me, by calling out any of the numbers, in response to which I would attempt to immediately give the corresponding word. Again, the students were consistently surprised by the speed at which I could easily carry this out after only a few minutes. After a few such tests, I would invite the opposite, asking students to give a word for which I would provide the corresponding number, and as a final test I would invite students to call out either a number or a word, to which I would, by that stage, be able to provide the paired item almost immediately. My observation, in class after class, was that this demonstration was engaging and interesting to the students, and that they were curious to know by what kind of trickery I was able to carry it out.

On the chalk board, I would show how I had mnemonically connected the pairings. For example, to draw on the pairings from Figure 1, I would draw a tall, 
exaggeratedly stretched-out number 1, with a similarly long, impractical ovalshaped clock face next to it, indicating the connection I had created between 1 and clock. I might then draw stick-figure angels sitting upon a cloud in heaven (explaining the phonetic connection between "heaven" and "seven") having a conversation. (A conversation in heaven equals seven.) Next, perhaps, a ladder made by drawing rungs between each of the elongated digits in the number 11. Students would often indicate their interest in each mnemonic, as though a magician was revealing how he had performed the trick. Some explanations required more drawing, for example, number 18, which needed to connect first with high school graduation (for the reason given above), then to an image of celebrating graduation with friends, family and teachers in Starbucks (of all places), and thus to coffee (18, high school graduation, graduation party at Starbucks, coffee). For such longer and more disjointed mnemonics, assurances were given that by simply rehearsing them a few times, the processing time reduces to as close to immediate as the simpler connections. The key, I explained, was to make the connections funny or ridiculous.

\subsubsection{Practical experience}

Students were next asked to form groups of five or six, each of which was given a small card featuring a table of similarly simple target Japanese words paired with numbers. An example is given in Figure 2, which lists the Japanese words for young, snow, bite, itchy, shoe, etc. One group member was to be the "teacher," who was to verbally teach the pairings to the other members without them seeing or reading the card. The others would attempt to learn the pairings, as had been demonstrated, through creating and rehearsing mnemonic connections, which they were free to create and discuss together. Importantly, this practice activity was to take place entirely in Japanese, with no second-language burden, simply for the sake of practising the creative cognitive skills required for the mnemonic technique. The few minutes that this task took was, in lesson after lesson, a raucous din of laughing as students created, shared and rehearsed funny and ridiculous mnemonics.

\subsubsection{Applying the method to vocabulary study}

When each group appeared to have successfully memorised their list, I would call the class to attention and then make the claim that studying English vocabulary was exactly the same as the funny, boisterous activity they had just been enjoying. Rather than connecting a word to a random number, I asserted that vocabulary study can be thought of as connecting a word to a random arrangement of sounds/phonemes. Three examples that I had once created in a study session of my own were then presented.

On screen, an image of a heavily polluted waterway was displayed, with the explanation that rather than connecting this concept (pollution) to a random number, as we had been doing in the activities, as a learner of Japanese I had needed to connect it to the syllables "o" and "sen" (the Japanese osen, meaning "pollution"), which from my position as a non-Japanese speaker were simply

Vocabulary Learning and Instruction, 9 (1), 80-93. 


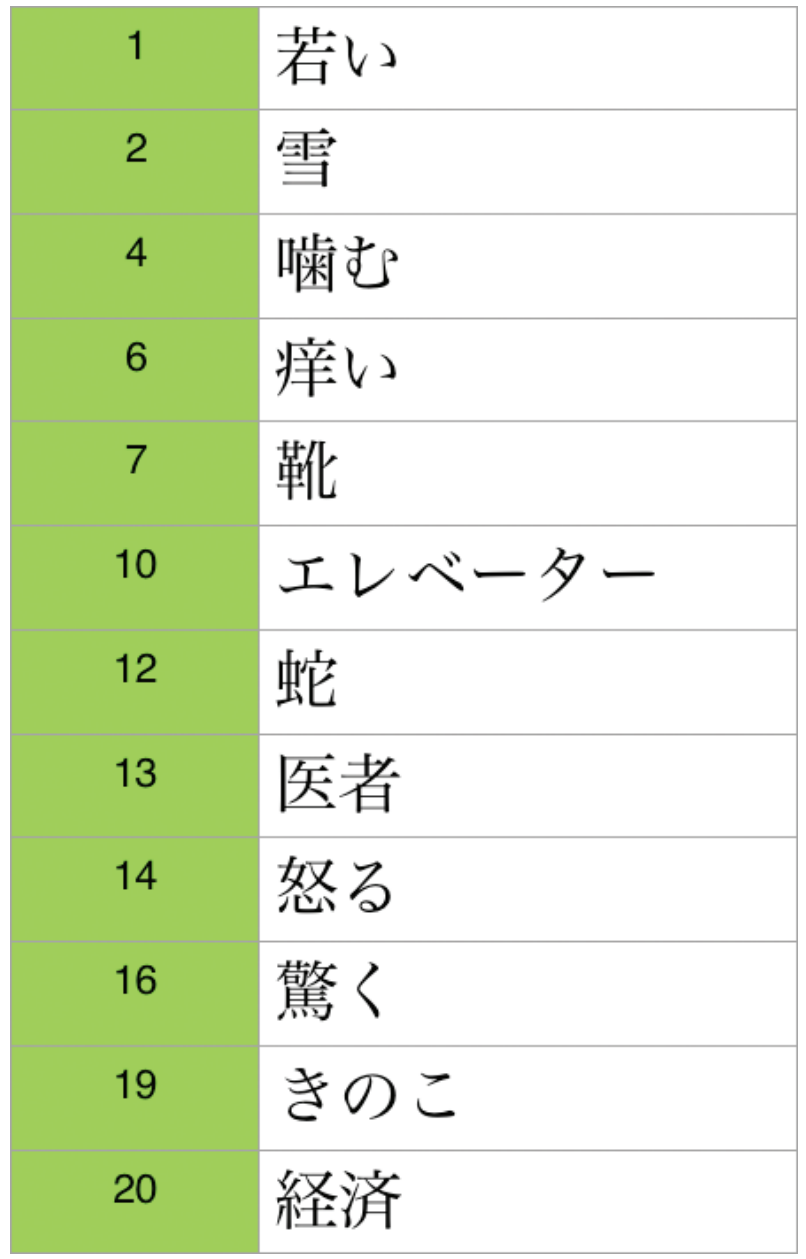

Figure 2. Example of a card produced for student groups to practise the strategy.

two random syllables that had no more connection with the concept of pollution than any random number would have. I explained that I had recognised osen as sounding similar to the Japanese word onsen, the famous natural hot-spring baths enjoyed throughout Japan. I then suggested the viscerally incongruent mental image of a disgustingly polluted onsen, that is, a typically beautiful natural scene ordinarily associated with cleanliness, being ruined by litter, chemicals, discoloration, even effluent - thereby creating a compelling mnemonic connection: pollution, polluted onsen, onsen, osen. The next slide showed school uniforms, which I explained, I had needed to connect to the meaningless (to a learner) arrangement of the syllables sei, $f u$, and $k u$ (the Japanese word seifuku, uniform). I had done so by noticing that the first two, "seifu," sounded similar to the English word "safe." Thus "uniform" could connect to a "safe" place, such as a school. Uniform, school uniform, school, safe place, "seifu," seifuku. With repetition and practice, the connection would eventually become almost instant. Finally, I demonstrated 
connecting the concept of "handshake" with the Japanese word akushu by noticing that the final syllable, shu, sounded like the English "shoe," and drew stickfigure characters attempting to shake hands whilst wearing shoes on their hands. Having given the students experience in thinking laterally and creatively through the practical experience stage, the presentation of example mnemonics from my own study appeared to be meaningful and garnered many laughs, whereas in previous semesters, in lessons without a practical component, there had seemed to be confusion, disinterest and miscomprehension during such explanations.

Finally, a video that I had created of myself learning Japanese vocabulary with the aid of word cards, using this kind of mnemonic approach, was shown. This was intended to demonstrate the applicability of mnemonics in a real-world learning situation of a kind with which the students had had experience. This 12-minute video, which had previously been shown to classes with good effect (Paton, 2015), shows the mnemonic approach being used to turn an actual vocabulary study session into a fast and enjoyable game-like experience. It was hoped that doing so would create in the students a desire to try mnemonics in their own vocabulary study, which was to begin in the following week's class.

This lesson was given in 11 separate classes across two semesters in 2018, with students from such academic departments as Sports Science, Engineering, Commerce and English.

\section{Research Questions}

Designing the lesson around number/word pairings, which had been a means of making the mnemonic approach accessible and free of any second-language complications, meant that there was a risk that the students might not have been persuaded regarding the applicability of the approach to vocabulary study. There was also a concern that while the students might find the exercise fun, they might leave the lesson still not feeling capable of applying what they had seen and practised, that is, coming up with their own mnemonics. To ascertain whether such concerns were legitimate, and whether perhaps the lesson plan needed to be further altered, a survey was designed that would hopefully answer the following research questions:

1. Was the lesson effective in presenting mnemonics as a vocabulary learning strategy that students could utilise effectively and enjoy?

2. Was the strategy new or novel to the students?

3. Did the students perceive and recognise the relevance between the number/ word exercises and actual second-language vocabulary study?

4. Did the lesson leave students feeling prepared and motivated to try using a mnemonic approach in their vocabulary study?

\subsection{The Survey}

A short, six-question survey was created that the students could complete on their cell phones at the start of the following week's lesson. It was created in Google Forms and linked to from the class website. Four of the questions asked 
for responses on a four-point Likert scale, and one was a "yes/no" question. The questions were translated into Japanese by a native speaker, and students were invited to optionally provide additional comments in Japanese. The questions were preceded by a short paragraph in Japanese explaining that students were not required to participate in the survey if they didn't want to and that all responses would be anonymous, and informing them that their responses might form part of the teacher's research and that proceeding with the survey would be taken as consent for that to occur. The survey took little more than 2 minutes for most students to complete.

\subsection{Measurement and discussion}

A total of 361 students completed the survey. The questions and responses are given below.

The response to question 1, in Table 1, demonstrated that $97 \%$ of students thought that the number/word pairings activity did indeed have relevance to vocabulary study, with $62 \%$ giving the most affirmative response. This answered research question number 3: concerns that the students would not perceive the method's applicability to vocabulary study turned out to have been misplaced. There appears to have been no cost in initially bypassing second-language vocabulary and instead introducing the mnemonic strategy indirectly before connecting it to vocabulary study once it had been witnessed and experienced.

Question 2, in Table 2, conclusively answered the second research question, which sought to find whether or not the strategy was novel. It also confirmed the findings of Schmitt (1997) and Little and Kobayashi (2015). Eighty-three per cent

Table 1. Survey Question 1, Perceived Relevance of the Strategy

(1) Last week I showed you a memory-strategy activity.

I memorised word/number combinations, and then I had you try it in groups.

Later, I said that the technique was very closely related to vocabulary study.

Did you see the connection between the memory-strategy and vocabulary learning, or do you think that the memory-strategy I showed has no relevance to learning vocabulary?
a: Yes, the relevance is clear.
$224(62.0 \%)$
Relevance
$97.0 \%$
$\mathrm{b}$ : There is some connection.
$126(34.9 \%)$ perceived:
c: The connection is weak, it doesn't really
$9(2.5 \%)$
Relevance
$2.5 \%$
relate to vocabulary study. doubted:
$\mathrm{d}$ : Vocabulary learning is completely $\quad 0(0 \%)$

different to the memory strategy you

showed. The demonstration was irrelevant.

Did not answer

$2(0.5 \%)$

$0.5 \%$

Table 2. Survey Question 2, Prior Knowledge of the Strategy

(2) Had you been taught the memory strategy before?
a: Yes
$60(16.6 \%)$
b: No
$300(83.1 \%)$
Did not answer
$1(0.3 \%)$

Vocabulary Learning and Instruction, 9 (1), 80-93. 
of students had not been taught what has long been known to be one of the most effective vocabulary learning strategies. Assuming this is also true of previous years' class members, this finding also goes some way to explaining why earlier attempts to teach the strategy by simply giving examples of mnemonics had fallen flat. It also explains the discernible interest in the initial teacher demonstration and the surprise at its speedy results. Having never been taught to memorise this way, that is, without copious repetition, establishing connections so quickly may well have been surprising and compelling.

A goal for the lesson had been to demonstrate that the mnemonic strategy, with its incorporation of humour, exaggeration, and absurdity, is more enjoyable than brute-force repetition-based memorisation. Table 3, showing the response to question 3 , indicates that the number/word pairing activity demonstrated this aspect of the strategy effectively. This, and survey question 4, answered research question 1, as to whether the lesson was effective in presenting mnemonics as a vocabulary learning strategy that students could utilise effectively and enjoy.

The questions shown in Tables 4 and 5 were intended to address research question 4, namely whether the students were left feeling prepared and motivated to try using a mnemonic approach in their vocabulary study. Seventy-two per cent of students indicated that they had gained some degree of confidence in their ability to utilise the strategy.

Whilst it might have been hoped that more than just $20.5 \%$ of students would answer that they would definitely use the strategy in their upcoming vocabulary study, an additional $67.6 \%$ reporting that they "might" use it can be viewed as confirmation that the lesson indeed left students feeling at least somewhat motivated

Table 3. Survey Question 3, Enjoyment of the Strategy

\begin{tabular}{lccc}
\hline (3) When you tried the memory strategy in your groups, was it enjoyable? & \\
a: Very enjoyable & $181(50.1 \%)$ & Enjoyable & $93.4 \%$ \\
b: OK & $156(43.2 \%)$ & & \\
C: Not really & $13(3.6 \%)$ & Not enjoyable & $4.4 \%$ \\
d: Not fun at all & $3(0.8 \%)$ & & \\
Fid not answer & $8(2.2 \%)$ & & $2.2 \%$ \\
\hline
\end{tabular}

Table 4. Survey Question 4, Confidence in Creating Mnemonics

(4) The demonstration and video was designed to show you how using funny images, or similarsounding words, can help create a connection between new English words and your existing knowledge.

Are you confident that you can create mnemonic connections between English words and their meanings?

\begin{tabular}{lccc} 
a: Very confident that I can create such images & $70(19.4 \%)$ & Confident & $72.6 \%$ \\
or connections & $192(53.2 \%)$ & & \\
b: Somewhat confident, and I intend to try it & $95(26.3 \%)$ & Not confident & $27.1 \%$ \\
c: Not very confident & $3(0.8 \%)$ & & \\
d: Not at all confident & $1(0.3 \%)$ & & $0.3 \%$ \\
Did not answer & & \\
\hline
\end{tabular}

Vocabulary Learning and Instruction, 9 (1), 80-93. 
Table 5. Survey Question 5, Intention to Utilise the Strategy

(5) Do you think you will use such a memory strategy to study vocabulary this semester?

a: I will definitely use a mnemonic strateg approach $74(20.5 \%)$ Positive towards utilising $\quad 88.1 \%$

b: I might

$244(67.6 \%)$

c: I probably won't

d: I definitely won't

$40(11.1 \%)$ the strategy

Did not answer

$1(0.3 \%)$

Negative towards

$11.4 \%$

$2(0.5 \%)$

$0.5 \%$

to try mnemonics. Whether or not their intentions would later turn into real action, of course, is a different matter.

\section{Conclusion}

There are many reasons behind Japanese students' tendency not to utilise mnemonic techniques for learning vocabulary. This study demonstrates that with the right approach, one that minimises second-language complications and which also involves a fun practice activity, teachers can present mnemonics as an effective and enjoyable strategy that students will want to utilise. Demonstrating and practising word/number pairings turned out to have been an effective way to introduce mnemonics and inspire students to take advantage of mnemonic strategies in their own vocabulary study. The students enjoyed using the strategy and saw its relevance to vocabulary study. Further research might reveal whether the students' initial agreeable attitude to mnemonics translated into actual and sustained usage. The survey responses indicated that this lesson plan achieved its intended results. Teachers who would like to introduce mnemonics as a vocabulary learning strategy are well-advised to try such an approach.

\section{References}

Amiryousefi, M., \& Ketabi, S. (2011). Mnemonic instruction: A way to boost vocabulary learning and recall. Journal of Language Teaching and Research, 2(1), 178-182. doi: 10.4304/jltr.2.1.178-182

Atkinson, R. C. (1975). Mnemotechnics in second-language learning. American Psychologist, 30(8), 821-828. doi: 10.1037/h0077029

Barcroft, J., Sommers, M., \& Sunderman, G. (2011). Some costs of fooling Mother Nature: A priming study on the keyword method and the quality of developing L2 lexical representation. In P. Trofimovic \& K. McDonough (Eds.), Applying priming research to L2 learning and teaching: Insights from psycholinguistics (pp. 49-72). Amsterdam: John Benjamins.

Brahler, C. J., \& Walker, D. (2008). Learning scientific and medical terminology with a mnemonic strategy using an illogical association technique. Advanced Physiology Education, 32, 219-224. doi: 10.1152/advan.00083.2007

Burns, A. (2010). Doing action research in English Language Teaching. New York: Routledge. 
Kitano, M. L. \& Chiba, K. (2019). Comparing the effectiveness of word cards and list learning with Japanese learners of English. Vocabulary Learning and Instruction, 8(1), 70-75.

Little, A., \& Kobayashi, K. (2015). Vocabulary learning strategies of Japanese life science students. TESOL Journal, 6(1), 81-111. doi: 10.1002/tesj.141

O’Malley, J. M., \& Chamot, A. U. (1990). Learning strategies in second language acquisition. Cambridge University Press.

O’Malley, J. M., Chamot, A. U., Stewner-Manzares, G., Kupper, L., \& Russo, R. P. (1985). Learning strategies used by beginning and intermediate ESL students. Language Learning, 35(1), 21-46. doi: 10.1111/j.1467-1770.1985. tb01013.x

Ott, C. E., Butler, D. C., Blake, R. S., \& Ball, J. P. (1973). The effect of interactive-image elaboration on the acquisition of foreign language vocabulary. Language Learning, 2, 197-206. doi: 10.1111/j.1467-1770.1973.tb00655.x

Oxford, R. (1990). Language learning strategies: What every teacher should know. New York: Newbury House.

Paton, S. (2015). Strategy instruction for independent vocabulary study through a teacher-produced video. Independence, 62, 15-22.

Paul, K. (1996). Study smarter, not harder. Petaling Jaya: Advantage Quest Publications.

Pillai, N. R. (2004). Using mnemonics to improve vocabulary, boost memory and enhance creativity in the ESL classroom. The English Teacher, 33, 62-83.

Pressley, M., Levin, J. R., \& Delaney, J. D. (1982a). The mnemonic keyword method. Review of Educational Research, 52, 61-91. doi: 10.3102/00346543052001061

Pressley, M., Levin, J. R., \& Miller, G. E. (1982b). The keyword method compared to alternative vocabulary learning strategies. Contemporary Educational Psychology, 7, 50-60. doi: 10.1016/0361-476X(82)90007-8

Raugh, M. R., \& Atkinson, R. C. (1975). A mnemonic method for learning a second-language vocabulary. Journal of Educational Psychology, 67(1), 1-16. doi: $10.1037 / \mathrm{h} 0078665$

Rubin, J. (1975). What the "good language learner" can teach us. TESOL Quarterly, 9, 41-51. doi: 10.2307/3586011

Schmitt, N. (1997). Vocabulary learning strategies. In N. Schmitt \& M. McCarthy (Eds.), Vocabulary: Description, acquisition and pedagogy (pp. 199-227). Cambridge University Press.

Schmitt, N. (2000). Vocabulary in language teaching. Cambridge University Press.

Shapiro, A. M., \& Waters, D. L (2005). An investigation of the cognitive processes underlying the keyword method of foreign vocabulary learning. Language Learning, 9(2), 129-146. doi: 10.1191/13621688051r151oa

Solso, R. L. (1995). Cognitive psychology (4th Ed.). Boston, MA: Allyn and Bacon.

Stern, H. H. (1975). What can we learn from the good language learner? Canadian Modern Language Review, 34, 304-318. doi: 10.3138/cmlr.31.4.304 
Thompson. I. (1987). Memory in language learning. In A. Wenden \& J. Rubin (Eds.), Learner strategies in language learning (pp. 15-30). Englewood Cliffs, NJ: Prentice-Hall.

van Hell, J. G., \& Mahn, A. C. (1997). Keyword mnemonics versus rote rehearsal: Learning concrete and abstract foreign words by experienced and inexperiences learners. Language Learning, 47(3), 507-546. doi: 10.1111/0023-8333.00018

Wang, A. Y., \& Thomas, M. H. (1995). Effects of keyword on long-term retention: Help or hindrance? Journal of Educational Psychology, 87(3), 468-475. doi: 10.1037/0022-0663.87.3.468 